Tumefactive gallbladder sludge at US: prevalence and clinical importance. Kim M, Kang TW, Jang KM et al. Radiology 2016; DOI: 10.1148/radiol.2016161042

This large study found tumefactive sludge in the gallbladder in 107 cases out of over 100,000 and, of these, 15 were actual malignancies. The risk factors included old age and being female. The researchers acknowledge gallbladder cancer is rare but careful evaluation is required when tumefactive sludge is seen on ultrasound.

Imaging surveillance in patients after a benign fine-needle aspiration biopsy of the thyroid: associated cost and incidence of subsequent cancer. Becker-Weidman DJ, Malhotra N, Reilly DF, et al. AJR 2017; 208: 358-361.

This group followed up 1685 patients who had had an initial thyroid fine needle aspiration (FNA) with benign results. They found that nearly half continued to have expensive surveillance including further FNA, MRI, CT, ultrasound and scintigraphy. Mean follow-up was for seven years during which time there were only 19 diagnoses of cancer, at a cost of over $\$ 46,000$ each.

The upturned superior mesenteric artery sign for firsttrimester detection of congenital diaphragmatic hernia and omphalocele. Lakshmy RS, Agnees $\mathrm{J}$ and Rose N. J Ultrasound Med 2017; DOI: 10.7863/ultra.16.04047

In seven cases this team noted that, in the first trimester fetus, the course of the superior mesenteric artery was altered in the presence of congenital diaphragmatic hernia $(\mathrm{CDH})$ and omphalocele. They suggest it may be a helpful sign for diagnosing CHD if there is a suspicion of a thoracic mass or mediastinal shift. Early diagnosis may facilitate earlier genetic testing.

Carotid disease at age 73 years and cognitive change from age 70 to 76 years: a longitudinal cohort study. Wardlaw JM, Allerhand M, Eadie E, et al. J Cereb Blood Flow Metab 2016; DOI: 10.1177/ $0271678 X 16683693$

These researchers from Edinburgh investigated 866 older people and found that vascular stiffening rather than narrowing of the internal carotid artery (ICA) lumen adversely influenced cognitive processing speeds. Their findings may help target treatment for age-related cognitive decline.

Malignancy risk of sonographically benign appearing purely solid adnexal masses in asymptomatic postmenopausal women. Alcazar JL, Pascual MA, Marquez R, et al. Menopause 2017; DOI: 10.1097/ GME.0000000000000814

Solid pelvic masses in 99 postmenopausal women usually turned out to be fibromas, fibrothecomas, thecomas, dermoid cysts or Brenner tumours. Only two were primary invasive cancers. Therefore, the authors suggest that since the risk of malignancy is very low, asymptomatic postmenopausal women with benignlooking adnexal lumps may be managed conservatively.

The value of homemade phantoms for training veterinary students in the ultrasonographic detection of radiolucent foreign bodies. Mariano Beraldo C, Rondon Lopes É, Hage R, et al. Adv Physiol Educ 2017; 41: 94-98.

A homemade phantom comprising gelatin- or meatembedded socks, balls and lolly stick splinters helped veterinary students to visualise and recognise foreign bodies commonly ingested by our furry friends. An excellent inexpensive learning experience which was, no doubt, fun too.

Integration of a low-cost introductory ultrasound curriculum into existing procedural skills education for preclinical medical students. Maloney L, Zach K, Page C, et al. J Ultrasound Med 2017; 36: 367-373.

Following on from the veterinary students, this team developed an effective phantom for medical students that cost only a few cents (USA) per trainee but was filled with grapes and olives rather than socks. Over just four teaching sessions, basic navigation and identification skills were improved and refined.

Ultrasound in undergraduate medical education: a systematic and critical review. Feilchenfeld Z, Dornan T, Whitehead C, et al. Med Educ 2017; DOI: 10.1111/ medu. 13211 
However..., here's an interesting article questioning the temporal and financial costs of such activities described above. There are many calls for ultrasound training to be included in undergraduate medical curricula, but this multinational team reviewed hundreds of papers advocating it and found little or no empirical evidence to support it.

Screening for thyroid cancer in survivors of childhood and young adult cancer treated with neck radiation. Tonorezos ES, Barnea D, Moskowitz CS, et al. $J$ Cancer Survivorship 2016; DOI: 10.1007/s11764-0160588-6

Based on surveillance of nearly 600 adult survivors of cancer experienced in childhood or young adulthood whose necks were exposed to radiation therapy, this team concludes that an annual physical examination may be all that is required to monitor them. Routine ultrasound for thyroid cancer screening is not supported.

Developing a knowledge base to support the annotation of ultrasound images of ectopic pregnancy. Dhombres F, Maurice P, Friszer S, et al. J Biomed Seman 2017; 8: 4. DOI: $10.1186 / \mathrm{s} 13326-017-0117-1$.

This Anglo-French collaboration recognises the heterogeneity in staff training in ultrasound, and arguably the minefield that is imaging for ectopic pregnancy. To aid diagnosis they developed a 'decision support system' and a method for standardising the labels on ultrasound images taken for this condition. They suggest that their method may be transferable for other conditions in obstetrics and gynaecology.

Dilemmas in the management of screen-detected lesions in patients at high risk for pancreatic cancer. Ibrahim IS, Bonsing BA, Swijnenburg RJ, et al. Fam Cancer 2017; 16: $111-115$.

A very interesting report highlighting very different outcomes for two patients at high risk of developing pancreatic cancer. Definitely worth reading. The takehome message is that patients need to be fully informed before joining a surveillance programme.

Cranial ultrasound findings in preterm infants predict the development of cerebral palsy. Skovgaard AL and Zachariassen G. Danish Med J 2017; 64: A5330.

This study included 249 preterm infants born at 32 weeks' gestation or earlier and, of those, 217 were still alive for follow-up in 2014 when they would have been between five and nine years old. Those with a neonatal ultrasound diagnosis of severe brain injury such as periventricular leukomalacia or periventricular haemorrhage infarction were more likely to later develop cerebral palsy.

\section{Hazel Edwards}

